\title{
Energy efficiency of industrial facilities as a factor of sustainable development of the country's economy
}

\author{
Tatiana Meshcheryakova ${ }^{1, *}$, Elona Tkacheva ${ }^{1}$ and Daria Kabanova ${ }^{1}$ \\ ${ }^{1}$ Moscow State University of Civil Engineering, Yaroslavskoe shosse, 26, Moscow, 129337, Russia
}

\begin{abstract}
The article identifies and postulates the importance of energy efficiency issues providing certain principles for the sustainable development of society, the national and world economy. The study analyzed the most energy-intensive types of economic activity - industrial production, which has a significant potential for energy conservation and energy efficiency from all energy consumers. The main indicator in the analysis of energy costs in industry is the structure of the costs of production and the energy balance for the respective types of production. The revealed regularities testify the availability of significant reserves of energy conservation and energy efficiency, which is available in certain types of industrial production: the manufacturing industry, the extraction of useful minerals, and the production and distribution of electricity, gas and water. The reduction in energy costs should concern not only technical, but also organizational changes. These recommendations are aimed at increasing the competitiveness of Russian products by reducing the material costs of energy. The most successful way to cope with the task of energy saving and increasing the energy efficiency of an industrial enterprise is the use of modern management mechanisms, including the international energy management standard ISO-50001.
\end{abstract}

\section{Introduction}

In the past decade, particular importance has been given to various issues which determine the sustainable development of the national and world economy. One of the most important issues ensuring sustainable development is the rational use of energy resources and the environmentally safe development of infrastructure. In view of this, such issues are reflected in the state policy of the country. "Rational Nature Management" and "Energy Efficiency, Energy Saving, Nuclear Energy" are included in the list of priority areas for the development of science, technology and technology in the Russian Federation. The great interest of researchers is directed to the issues related to energy saving in industrial enterprises, while observing the conditions of energy efficiency and ensuring their ecologically sustainable development.

\footnotetext{
*Corresponding author: t.meshcheryakova@mail.ru
} 
Large industrial enterprises have enormous energy costs. The increase in prices for energy resources leads to a rise in price of manufactured products, as the cost of the final product includes energy costs. The share of energy costs in the cost of Russian products is higher than in other countries, which can lead to low competitiveness of domestic products and equipment in the world market. Based on this, industrial objects are identified as the object of research.

There is a need to optimize the energy costs of industrial facilities, which is the target of the study. It requires competent professional management of energy resources and the development of a strategy for energy conservation and improving the energy efficiency of the enterprise. The strategy should include a set of measures aimed at reducing energy costs and taking into account the principles of environmental protection. These principles allow the impact of enterprises on the natural environment, based on environmental requirements [1]. At the same time, the reduction of the negative impact on the environment should be achieved on the basis of using the best available technologies taking into account economic and social factors.

Now it is given insufficient attention to the problem of energy saving in industrial enterprises This leads to serious problems: lack of working capital, high production costs and even some crisis in the production sector.

In order to identify the energy saving reserve and increase the energy efficiency of industrial enterprises and to develop management solutions, the following tasks must be solved:

- analyze the data on the structure of costs of various types of industrial production and identify the place of energy costs in this structure;

- analyze the energy costs of industrial production and identify the largest consumer of heat and electricity;

- identify the potential for energy conservation and energy efficiency of industrial facilities;

- develop recommendations for energy conservation and energy efficiency of industrial enterprises.

\section{Materials and methods}

To solve the problems set, following theoretical methods of investigation were used: axiomatic method, formalization method, general logical method.

In the course of the study, normative and legal documents were used, such as: Federal Law \# 7 "On Environmental Protection" and Federal Law \# 261 "On Energy Saving" [1, 2]. These documents are the forerunner of a variety of methodologies, standards and other documents regulating energy conservation, which improve energy efficiency and environmental regulation of all types of economic activities, including industrial enterprises.

To analyze the energy intensity of industrial enterprises, the data of the Annual Statistical Digest of the Federal State Statistics Service (Rosstat) were used [3]. To identify the potential for energy savings, the consolidated fuel and energy balance, published by Rosstat, is used. This balance is an important tool in the process of developing integrated long-term programs of energy conservation and energy efficiency.

\section{Results}

Based on the analysis of statistical data on the structure of costs for the production and sale of products (goods, works, services) by types of economic activity, one can identify the most energy-intensive production. 
Let's present the data on expenses at extraction of minerals (Figure 1):

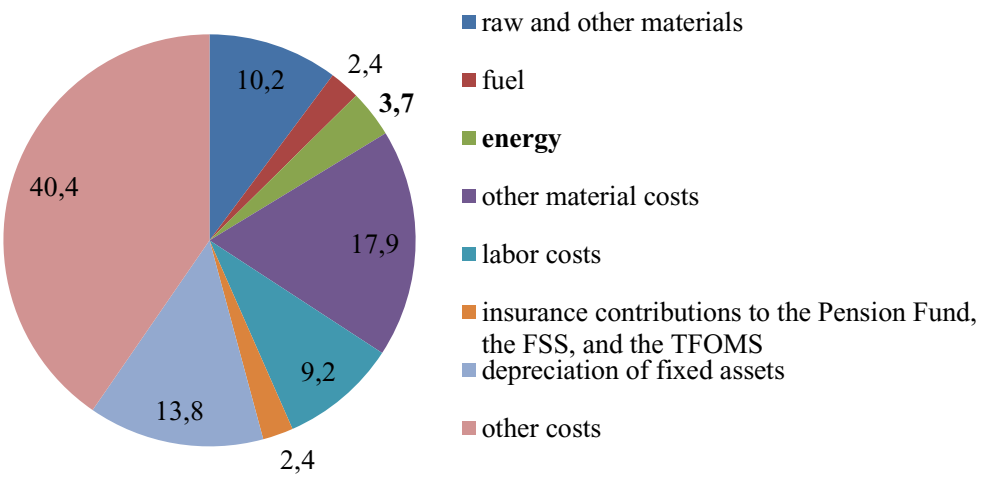

Fig. 1. Cost structure for mining operations.

The material costs of mining are approximately $34 \%$ of the total costs. The raw and the materials determine the main article of the material costs. The costs of fuel and energy are about $6 \%$ of the overall cost structure (including 3.7\% - energy costs).

One of the most energy-intensive types of economic activity in both the extractive and the entire industry is the extraction of oil and natural gas, corresponding to the data with the Rosstat energy balance (Figure 2):

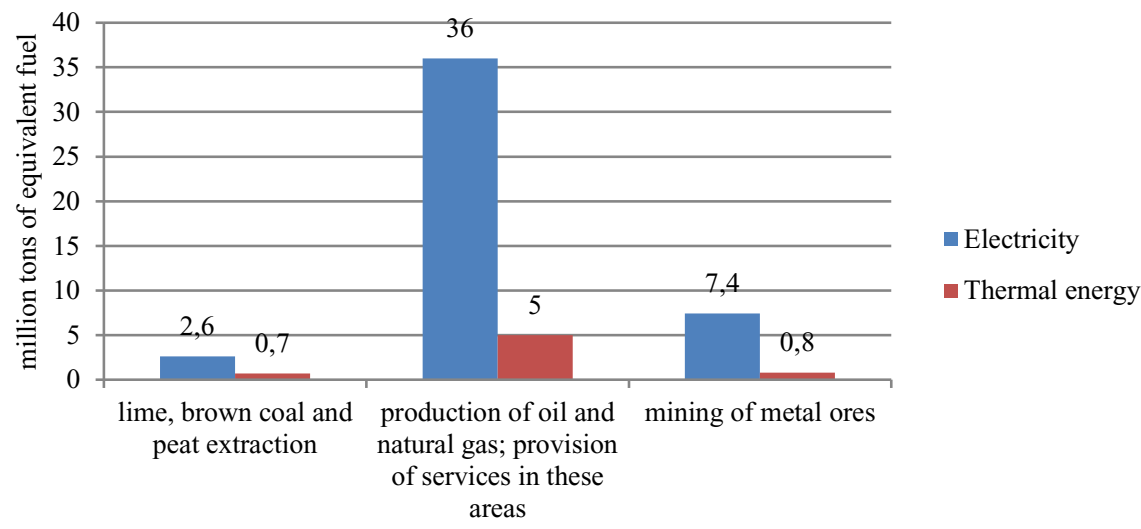

Fig. 2. The volume of consumption of heat and electric energy in the extractive industries.

Next, consider the cost structure of manufacturing industries (Figure 3).

The main part of the costs in manufacturing industries is the purchase of raw materials and other materials. Energy costs, despite the fact that they do not have such a value in the total aggregate of costs as raw materials and other materials necessary for the reproduction process, still affect the cost of production. It is also necessary to single out certain types of manufacturing industries for which the energy intensity is higher than the average statistical indicator. For example, the metallurgical industry and the production of finished metal products, as well as the chemical industry are considered to be energy-intensive ones. 


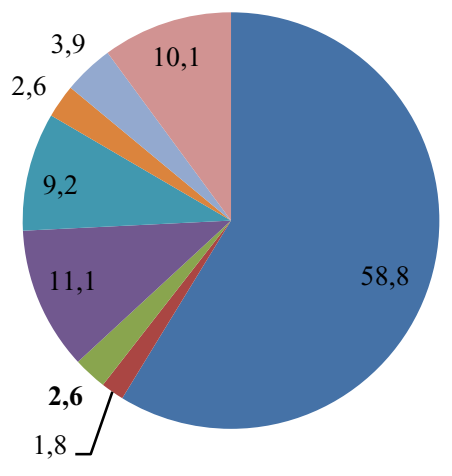

n raw and other materials

auel

energy

- other material costs

labor costs

insurance contributions to the Pension Fund, the FSS, and the TFOMS

depreciation of fixed assets

other costs

Fig. 3. Cost structure in manufacturing.

In confirmation of this, we give the data on energy costs in the manufacturing industry (Figure 4):

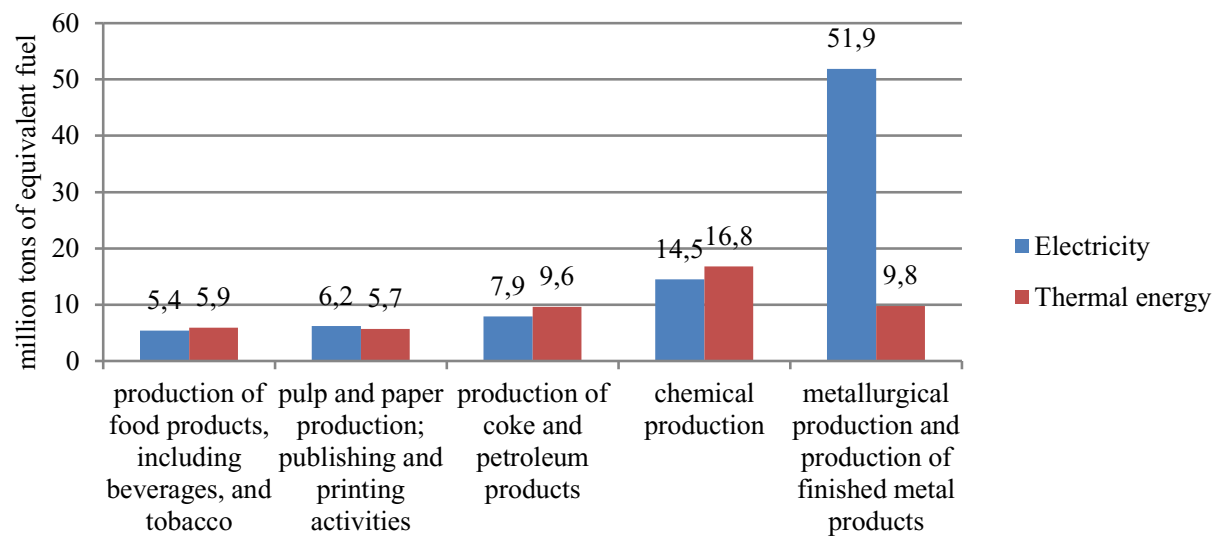

Fig. 4. The volume of heat and electric energy for manufacturing industries.

The most energy-consuming types of manufacturing industries are considered. As can be seen from Figure 4, metallurgical production and production of finished metal products are the most energy-intensive types of production. However, it is necessary to distinguish between energy consumption and energy intensity, since despite the fact that the total energy costs are the highest for manufacturing industries, this does not mean the highest energy intensity. Energy intensity involves the correlation of energy costs per unit of output.

Let's present the data on the cost structure for production and distribution of electricity, gas and water (Figure 5): 

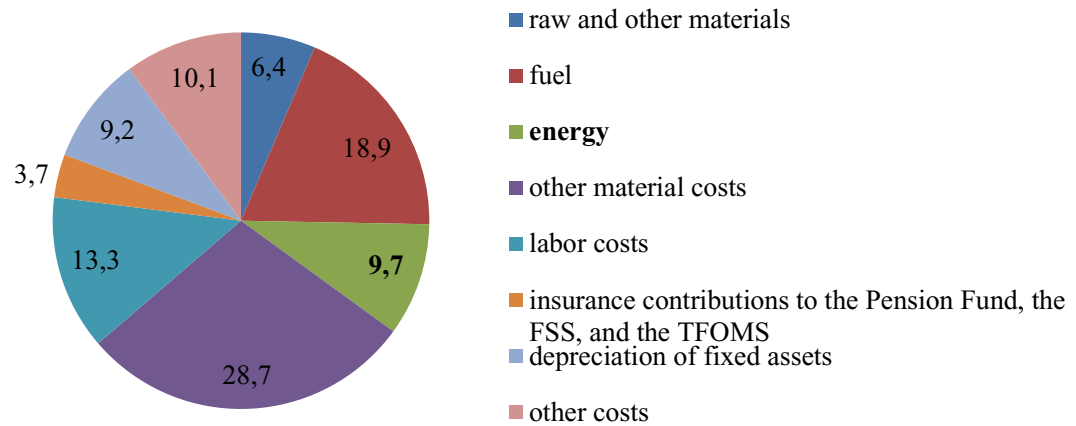

Fig. 5. Structure of costs of enterprises associated with the production and distribution of electricity, gas and water.

Taking into account all the data given earlier, it can be stated that the production and distribution of electricity, gas and water is the most energy-intensive production.

We present data on the cost of heat and electricity for this type of economic activity (Figure 6):

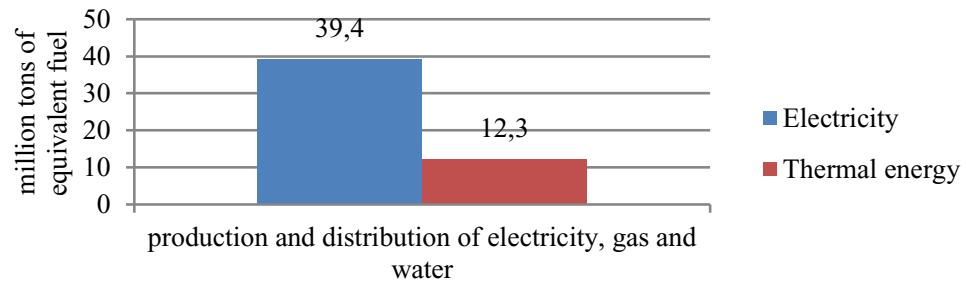

Fig. 6. The volume of heat and electric energy expended in the production and distribution of electricity, gas and water.

Next, we present data on the structure of costs in construction (Figure 7):

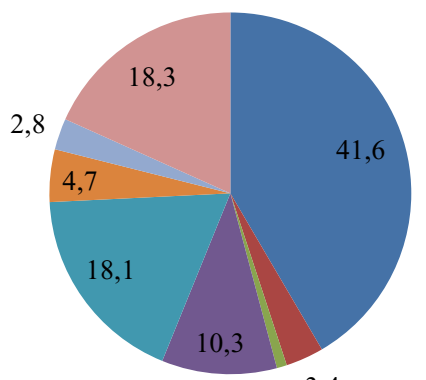

0,9 3,4 raw and other materials

fuel

wengy

- other material costs

alabor costs

n insurance contributions to the Pension

Fund, the FSS, and the TFOMS

depreciation of fixed assets

other costs

Fig. 7. Structure of costs of construction companies.

Based on the energy balance data, we give data on the cost of heat and electricity in construction (Figure 8): 


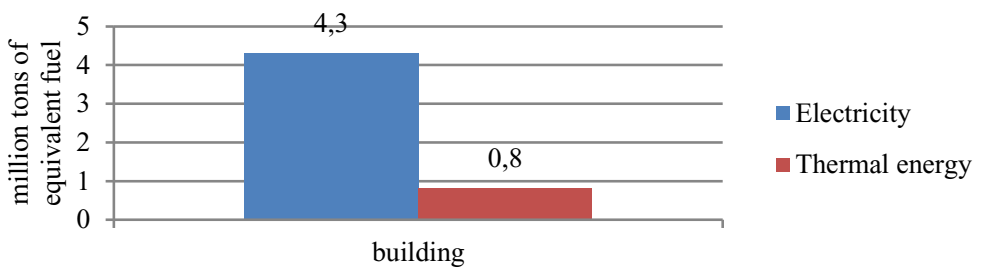

Fig. 8. The volume of heat and electric energy is spent for the manufacture of civil work.

The presented data indicates that construction is not an energy-intensive type of production. Like to the manufacturing industry, the raw materials and materials account for the largest costs. In the production of construction works, the main energy resource is electrical energy.

In addition to the opportunities associated with the technical re-equipment of production facilities and the increase in energy efficiency of production, it should be noted that there is a potential for energy conservation associated with the minimization of the losses in energy networks (Figure 9):

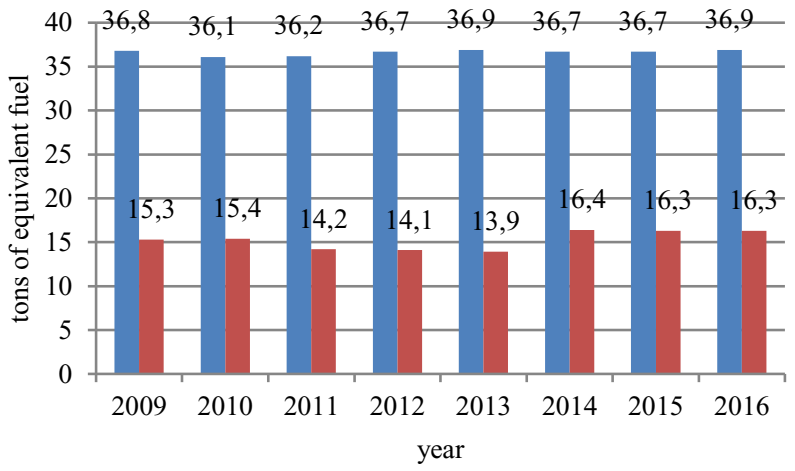

- electric power

- heat power

Fig. 9. Losses in energy at the stages of consumption and transportation.

Official statistics show that, despite the multiplicity of state energy saving measures, losses in the stages of consumption and transportation are not reduced.

\section{Discussion}

The obtained data on the volume of consumed energy resources, as well as on losses during transportation and consumption of energy, make it possible to conclude that the existing energy saving measures are not effective and new approaches are required to deal with issues related to sustainable development of the national economy.

An important stage in solving problems is the establishment of the Best Available Technologies Database (BAT) [5]. These technologies are determined on the basis of modern achievements of science and technology and the best combination of criteria for achieving environmental protection goals, provided that the technical feasibility of its application is available. Today, the task is to ensure an integrated approach to the implementation of BAT both in the framework of environmental and industrial policies, as well as the improvement of the state regulation system based on BAT. In the construction of such a system, a significant role is assigned to Rosstandart's activities and standardization mechanisms. 
However, BAT is the smallest tool that fits into the general policy of energy conservation and energy efficiency.

Of the particular importance there are the ISO-50001 energy management standards, which ensure the high efficiency of the energy management system (EMS) [6]. ISO-50001 is highly compatible with other international standards, such as ISO 18000, ISO 14000, ISO 9001, etc. According to ISO 50001: 2011, the regular organizational events include the steps reflected by the energy management model.

The goal of EMS is to provide the enterprise with a complete and structured management of the optimization of energy consumption. Technical innovations lead to more efficient use of energy resources in the organization, but their streamlining makes the process of energy saving and energy efficiency more sustainable and predictable, and improve the functioning of the company as a whole [7-10]. The introduction of EMS allows the implementation of a systematic approach into energy management.

Stages of creation and implementation of EMS in the enterprise should include:

- The rationale for the technical and economic feasibility of implementing this system;

- Development of a set of normative documents, the result of which should be the Standard of the enterprise for the management of energy costs. The set of normative documents should include:

- normative base, regulating responsibility, tasks, powers, mutual subordination both within the created structure, and its interaction with other structural subdivisions of the enterprise;

- technical documentation, methods of work;

- creation of a training program, maintaining the required level of knowledge, training and retraining of personnel;

- Creation of a technical base (devices, software);

- Creation of a separate subdivision with the function of the management of energy losses (energy management) in the structure of the enterprise.

- Information support of activities. This stage consists in explaining the goals and content of the EMS to the personnel of the enterprise $[11,12]$.

\section{Conclusions}

The conducted research allows to draw the following conclusions.

Analysis of the structure of costs for the production and sale of products (goods, works, services) by economic activities shows that energy costs are from 0.5 to $9.7 \%$ of total costs. The largest share of energy costs in total costs for production and sales, which characterizes energy intensity, is observed in the production and distribution of electricity, gas and water.

An analysis of the energy balance for different types of economic activity shows that the the industrial enterprises are the largest consumers. The manufacturing industry is the key consumer in the industry. In the manufacturing industry, the largest consumers are metallurgical production and the production of finished metal products, as well as chemical industry enterprises. On the second place among large energy consumers there are enterprises for the extraction of minerals. The largest consumer among the extracting enterprises are oil and natural gas production companies, as well as the service companies in these areas. On the third place among the large energy consumers are enterprises for the production and distribution of electricity, gas and water. Thus, these types of economic activity have the greatest potential for energy saving.

In order to save energy and increase the energy efficiency of industrial enterprises, it is necessary to implement energy-efficient policies and develop an energy strategy. Such a tool as energy management allows successfully implementing energy-efficient policies . For most companies in the Russian Federation, the introduction and implementation of EnMS is more 
closely related to the image or the requirements of legislation, and to a lesser extent is related to the intention to actually improve energy efficiency through its implementation. This is due not only to the small experience and quality of the implementation of this system, but also to the lack of a unified methodology for assessment of the actual impact of EMS on the economic efficiency of the organization.

\section{References}

1. On Environmental Protection, Federal Law №7 (2002)

2. On Energy Saving and on Improving Energy Efficiency and on Amending Certain Legislative Acts of the Russian Federation, Federal Law №261 (2009)

3. Federal State Statistics Service, Russian statistical yearbook (2017)

4. Federal State Statistics Service, Official statistics, Balance of energy resources (2017)

5. BURONDT, Best Available Techniques (2018)

6. International Organization for Standardization, ISO 50001-Energy management (2011)

7. N. Taskaeva, MATEC 106, 08093 (2017)

8. N. Harmathy, V. Murgul, Procedia Engineering, 165, 1845 - 1852 (2016) DOi10.1016/j.proeng.2016.11.932

9. V. Pukhkal, V. Murgul, IOP Conference Series: Earth and Environmental Science, 90, 012211 (2017) DOi - 10.1088/1755-1315/90/1/012211

10. V. Murgul, MATEC Web of Conferences, 73, 02001 (2016) DOi$10.1051 /$ matecconf $/ 20167302001$

11. State report power saving and increasing energy efficiency in the $R F$ (2017)

12. T. Blinova, MATEC 73, 07023 (2016) 